\title{
Tissue location of Vibrio antigen delivered by immersion to tiger shrimp (Penaeus monodon)
}

\author{
Hung-Hung Sung ${ }^{a}$, Yen-Ling Song ${ }^{b, *}$ \\ a Department of Microbiology, Soochow University, Taipei, Taiwan \\ ${ }^{b}$ Department of Zoology, National Taiwan University, Taipei, Taiwan
}

Accepted 23 April 1996

\begin{abstract}
Using an indirect fluorescent antibody technique, we traced the tissue location of heat-killed Vibrio vulnificus antigen delivered by immersion to tiger shrimp (Penaeus monodon). At selected time intervals ( $5 \mathrm{~min}, 3,6$ and $12 \mathrm{~h}$, and 1, 3, 7 and 14 days) following administration, we observed antigen uptake in hemolymph and tissues such as the gills, stomach, hepatopancreas, intestines, hematopoietic tissue and lymphoid organ, but not in the heart. In addition, we found some differences in time of appearance and amount of Vibrio antigen detected among these tissues. Various amounts of antigen were detectable in plasma and hemocytes 1 day following delivery, in the gills up to day 7 , in the hepatopancreatic and hematopoietic tissue to day 3 , in the stomach and midgut to the end of day 1 , in the hindgut for only $6 \mathrm{~h}$, and in the lymphoid organ from $6 \mathrm{~h}$ to 7 days; by day 14, the antigen was completely undetectable. According to the immunohistological results, we consider that Vibrio antigen is absorbed through the digestive and circulatory systems. The systemic, rather than local, defense system of tiger shrimp can be enhanced; however, this enhancement is only of short duration.
\end{abstract}

Keywords: Vibrio antigen; Tissue location; Tiger shrimp; Penaeus monodon; Immersion

\section{Introduction}

Vibriosis, a principal bacterial disease in shrimp, causcs shell disease, localized infections and bacterial septicemia (Lewis, 1973; Lightner and Lewis, 1975; Sindermann, 1977; Liao et al., 1985; Liu and Chen, 1988). Since 1986, there have been

\footnotetext{
* Corresponding author. Tel.: 886-2-3630231-3355; fax: 886-2-3660243; e-mail: song@ccms.ntuedu.tw.
} 
numerous occurrences of massive mortality in cultured tiger shrimp (Penaeus monodon) in Taiwan. Researchers have found that $80 \%$ of the bacteria isolated from these occurrences were Vibrio species (Liu and Chen, 1988; Song et al., 1993). Several studies have shown that Vibrio species are opportunistic shrimp pathogens that take advantage of such conditions as toxicoses, nutrient deficiencies, or viral infections (Lightner, 1983).

Several laboratories have developed Vibrio vaccines or immunostimulants for shrimp (Itami et al., 1989; Song and Sung, 1990; Itami et al., 1991; Sung et al., 1991; Itami et al., 1992a; Itami et al., 1992b). Our previous studies showed that both immersion and oral administration of $V$. vulnificus antigen enhance the growth rate of cultured tiger shrimp, therefore we suspect that certain disease resistance factors must be activated and are responsible for this enhancement of growth (Song and Sung, 1990; Sung et al., 1991). Immersion treatment with yeast beta-glucan was also demonstrated to enhance growth and vibriosis resistance in shrimp (Sung et al., 1994). Two microbicidal events, phenoloxidase activity and intrahemocytic production of superoxide anion, have been shown to be strengthened in such treated shrimp and are therefore probably correlated with disease resistance (Sung et al., 1996).

The aim of the present research was to elucidate whether Vibrio antigen or any other immunostimulant is absorbed by shrimp via immersion. We traced the tissue location and duration of heat-killed Vibrio vulnificus cells in tiger shrimp via the indirect fluorescent antibody technique. The results should contribute to the determination of the route and booster protocol for Vibrio antigen or immunostimulant application in the field.

\section{Matcrials and methods}

\subsection{Experimental animals}

Healthy out-looking tiger shrimp, Penaeus monodon, weighing approximately $20 \mathrm{~g}$ each, were obtained from the Tung-Kang Marine Laboratory in Pingtung, Taiwan, and were allowed to acclimate to aerated $2.5 \%$ seawater and $25^{\circ} \mathrm{C}$ for at least 2 days prior to each experiment. Shrimp densities were adjusted to four individuals per liter. Artificial feed was given three times each day.

\subsection{Antigen preparation}

Heat-killed V. vulnificus TG617 cells, isolated from diseased tiger shrimp (Song et al., 1990), were prepared according to procedures of Sung et al. (1993). Briefly, overnight-cultured cells were heated at $65^{\circ} \mathrm{C}$ for $1 \mathrm{~h}$ and examined for sterility of cell suspension using thioglycolate broth (Difco, Detroit, MI). They were then suspended in sterile seawater and the concentration was adjusted to $10^{7}$ cells $\mathrm{ml}^{-1}$ using a bacterial counting chamber. 

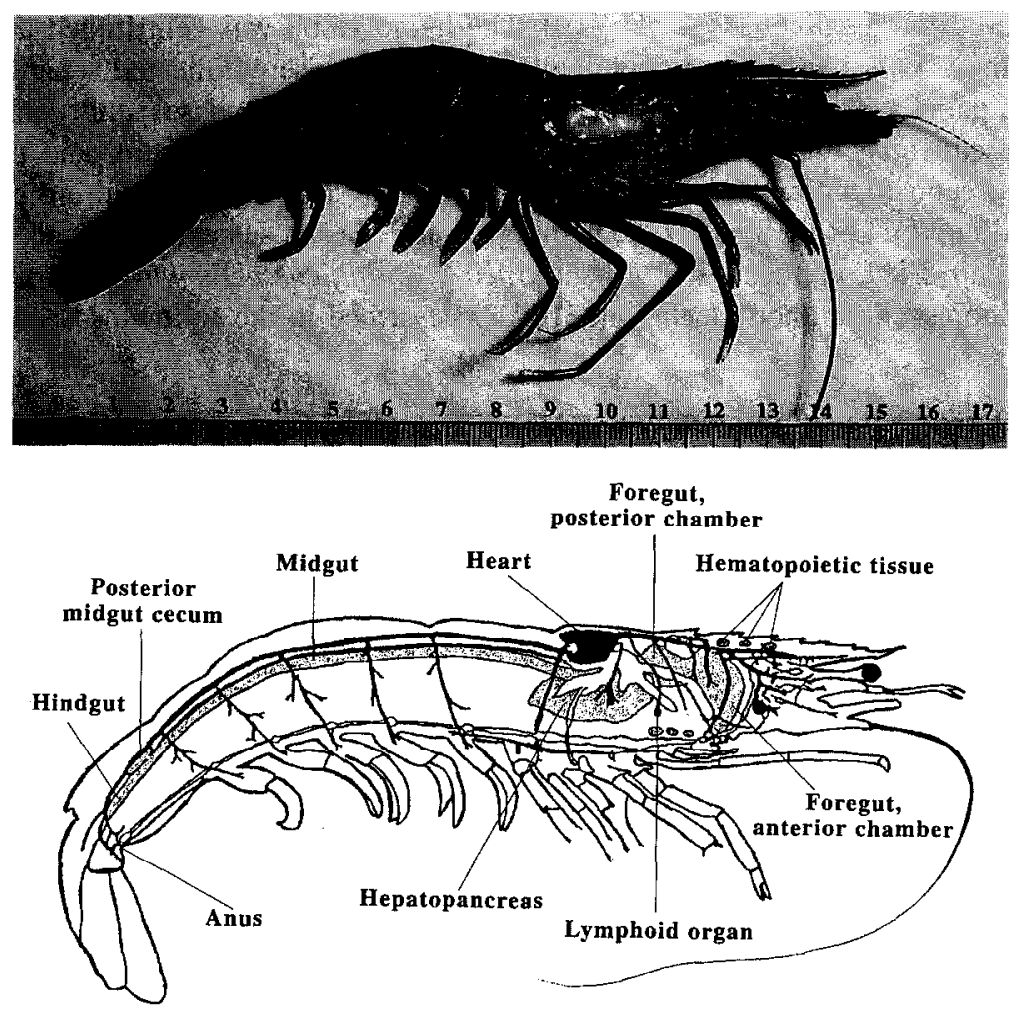

Fig. 1. The gross anatomy of penaeid shrimp. (a) A whole-body section of tiger shrimp (Penaeus monodon). (b) The diagrammatic representation of a penaeid shrimp is provided as a reference, except gills, to assist in the understanding of penaeid shrimp anatomical terminology (modified from Mclaughlin, 1980; Bell and Lightner, 1988).

\subsection{Immersion}

Experimental shrimp were immersed in the heat-killed antigen suspension, and control shrimp were immersed in sterile seawater, for $3 \mathrm{~h}$ at a density of two shrimp $1^{-1}$. Samples of two shrimp each were collected at $5 \mathrm{~min}, 3,6$, and $12 \mathrm{~h}$, and $1,3,7$, and 14 days following treatment to detect the distribution of Vibrio antigen in the hemolymph and tissues (Fig. 1).

\subsection{Hemolymph}

One milliliter of hemolymph was drawn from the pericardial cavity of each shrimp with a $2.5 \mathrm{ml}$ syringe (using a $26 \mathrm{G} \times 1 / 2$ in. needle) containing $0.5 \mathrm{ml}$ of $10 \%$ natural buffered formalin solution $(\mathrm{v} / \mathrm{v}, 10 \mathrm{ml}$ of formaldehyde solution in $90 \mathrm{ml}$ of $0.02 \mathrm{M}$ 
phosphate-buffered saline (PBS, $\mathrm{pH} 7.0)$ ). The hemolymph was centrifuged at $300 \times \mathrm{g}$ for $10 \mathrm{~min}$ at $4^{\circ} \mathrm{C}$, then the hemocyte pellet and plasma were collected separately. The hemocyte pellet was washed three times with $0.02 \mathrm{M}$ PBS, and suspended in $1 \mathrm{ml}$ of PBS. Subsequently, the plasma was centrifuged at $500 \times g$ for $5 \mathrm{~min}$, and the supernatant was centrifuged again at $12000 \times g$ for $10 \mathrm{~min}$ at $4^{\circ} \mathrm{C}$. The resulting pellet was suspended in $20 \mu \mathrm{l}$ of PBS. After the hemocytes and plasma suspensions were spread on slides and air dried, the detection of heat-killed $V$. vulnificus cells was performed by an indirect fluorescent antibody technique (IFAT) described in the following section.

\subsection{Immunohistological examination}

Whole specimens of both experimental and control shrimp tissues were fixed in Davidson's fixative for $48 \mathrm{~h}$, and the fixation effect was enhanced according to methods described by Bell and Lightner (1988). Our preliminary research showed that the conformation of Vibrio epitope was not altered by Davidson's fixative and it would be specifically recognized by anti- $V$. vulnificus mAb P3F10 which recognizes the surface epitope of $V$. vulnificus (Sung et al., 1993). Following dehydration and embedding in paraffin (Oxford Labware, St. Louis, MO), sections $5 \mu \mathrm{m}$ thick were prepared and placed on microscope slides. After deparaffinization and rehydration according to procedures of Evensen et al. (1991), the sections or hemolymph samples were washed with $0.01 \mathrm{M}$ PBS at $\mathrm{pH} 7.0$ for $10 \mathrm{~min}$, and incubated with a blocking solution containing $10 \%$ bovine serum albumin (BSA), $1 \%$ horse normal serum and $0.01 \%$ gelatin in PBST (0.1\% Tween 20 in $0.01 \mathrm{M}$ PBS, pH 8.0) for $20 \mathrm{~min}$. Following another washing with PBST for $10 \mathrm{~min}$, the sections were stained with ascitic fluid, which contains anti- $V$. vulnificus mAb P3F10, diluted to $1 / 1000$ with PBST containing 5\% $\mathrm{BSA}$, then kept at $37^{\circ} \mathrm{C}$ for $1 \mathrm{~h}$. After another 10 min washing with PBST, FITC-conjugated horse anti-mouse IgG (Vector Laboratories, Burlingame, CA) was applied to each section at a dilution of $1: 40$ in PBS containing $2 \%$ horse normal serum. To eliminate nonspecific binding between the anti-mouse IgG and shrimp tissues, the hepatopancreas, intestine and gills of fresh, unfixed shrimp were homogenized in acetone and then centrifuged, and the pellet was reacted with antiserum at room temperature for $30 \mathrm{~min}$ to remove the nonspecific binding materials of antiserum. The sections were then incubated for $30 \mathrm{~min}$ in darkness, rewashed with PBST, air dried, and counter stained with Evan's blue (0.05\%). Two sections from each shrinp were used as controls, one stained with $\mathrm{mAb}$ and the other with secondary antibody, to examine whether the appearance of fluorescence is a result of nonspecific binding of antibodies. Coverslips were mounted with fluorescent mounting medium (Vector Laboratories, Burlingame, CA). The presence and intensity of fluorescence, which reflected the relative antigen quantity, were examined in the different tissues using an epifluorescent microscope (Olympus BH-2) using incident light from an HBO $100 \mathrm{~W}$ high-pressure mercury lamp with a BP490 excitation filter in combination with a DM500 dichroic mirror and $\mathrm{AFC}+\mathrm{O} 515$ barrier filter. These filters give a peak excitation intensity of 435-490 nm. Photomicrographs were taken with a black-and-white film (FUJICOLOR, ASA 400). 
Table 1

Tissue locations of heat-killed $V$. vulnificus cells in tiger shrimp (Penaeus monodon) at different times following immersion

\begin{tabular}{llllllllll}
\hline Tissue & \multicolumn{7}{l}{ Fluorescent intensity post-immersion } \\
\cline { 2 - 9 } & $5 \mathrm{~min}$ & $3 \mathrm{~h}$ & $6 \mathrm{~h}$ & $12 \mathrm{~h}$ & $\mathbf{1}$ day & 3 days & 7 days & 14 days \\
\hline Plasma & + & + & + & + & + & - & ND & ND \\
Hemocyte & + & + & ++ & + & + & - & ND & ND \\
Gill & +++ & + & + & + & + & + & + & - \\
Stomach & +++ & ++ & ++ & + & + & - & - & - \\
Hepatopancreas & + & +++ & ++ & ++ & + & + & - & - \\
Midgut (anterior) & + & +++ & +++ & + & + & - & - & - \\
Midgut (posterior) & + & ++ & + & + & + & - & - & - \\
Hindgut & + & ++ & + & - & - & - & - & - \\
Hematopoietic tissue & + & + & + & + & + & + & - & - \\
Lymphoid organ & - & - & + & ++ & ++ & ++ & + & - \\
Heart & - & - & - & - & - & - & - & - \\
\hline
\end{tabular}

a Located in the central part of the hepatopancreas.

ND, not detected.
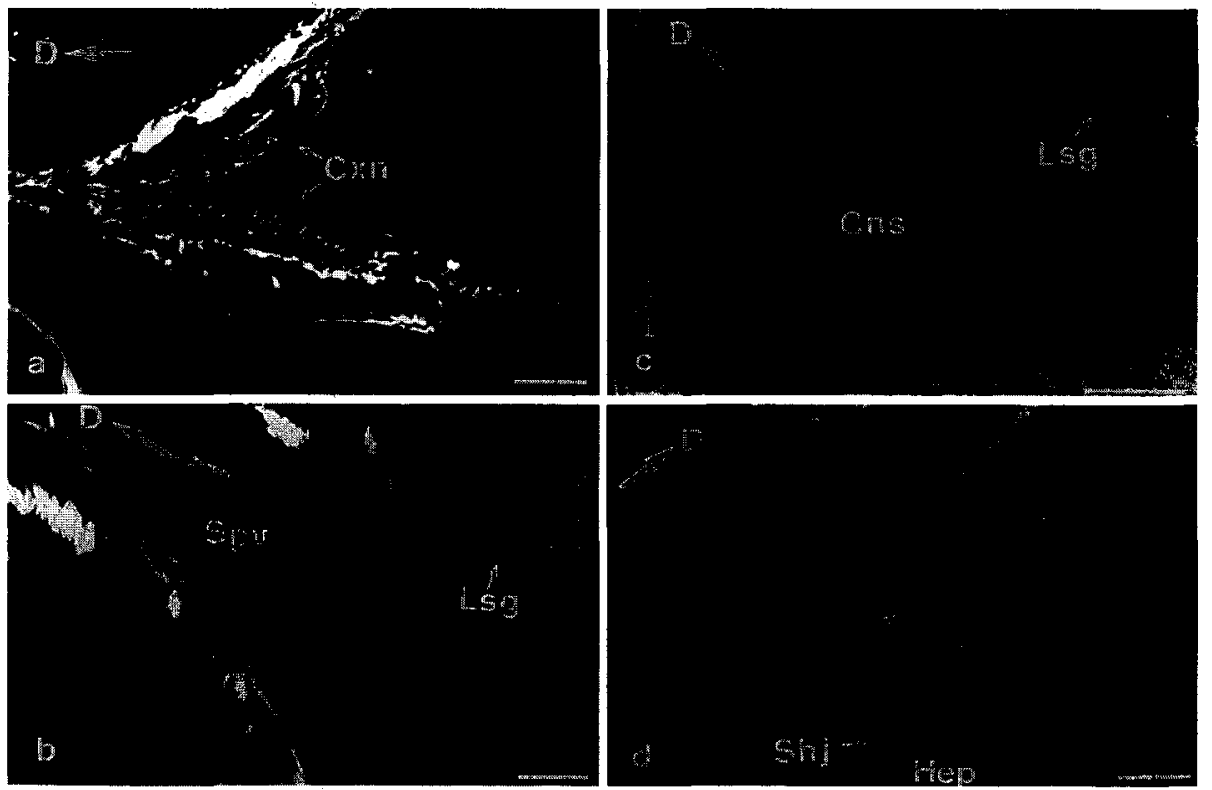

Fig. 2. Vibrio vulnificus heat-killed cells stained using an IFAT in the posterior chamber of a tiger shrimp stomach at $5 \mathrm{~min}(\mathrm{a})$ and $3 \mathrm{~h} \mathrm{((b)-(d))} \mathrm{following} \mathrm{delivery} \mathrm{via} \mathrm{immersion.} \mathrm{D,} \mathrm{dorsal} \mathrm{direction} \mathrm{of} \mathrm{the} \mathrm{body}$ indicated by arrow; Cns, spongy connective tissue; Cxn, cuticle sublayers; Hep, hepatopancreas; Lsg, longitudinal inter-setal grooves; Shj, stomach-hepatopancreatic junction; Spv, ventral subchambers. (a) Bar $=100 \mu \mathrm{m}$; (b) $\_$(d) bar $=25 \mu \mathrm{m}$. 


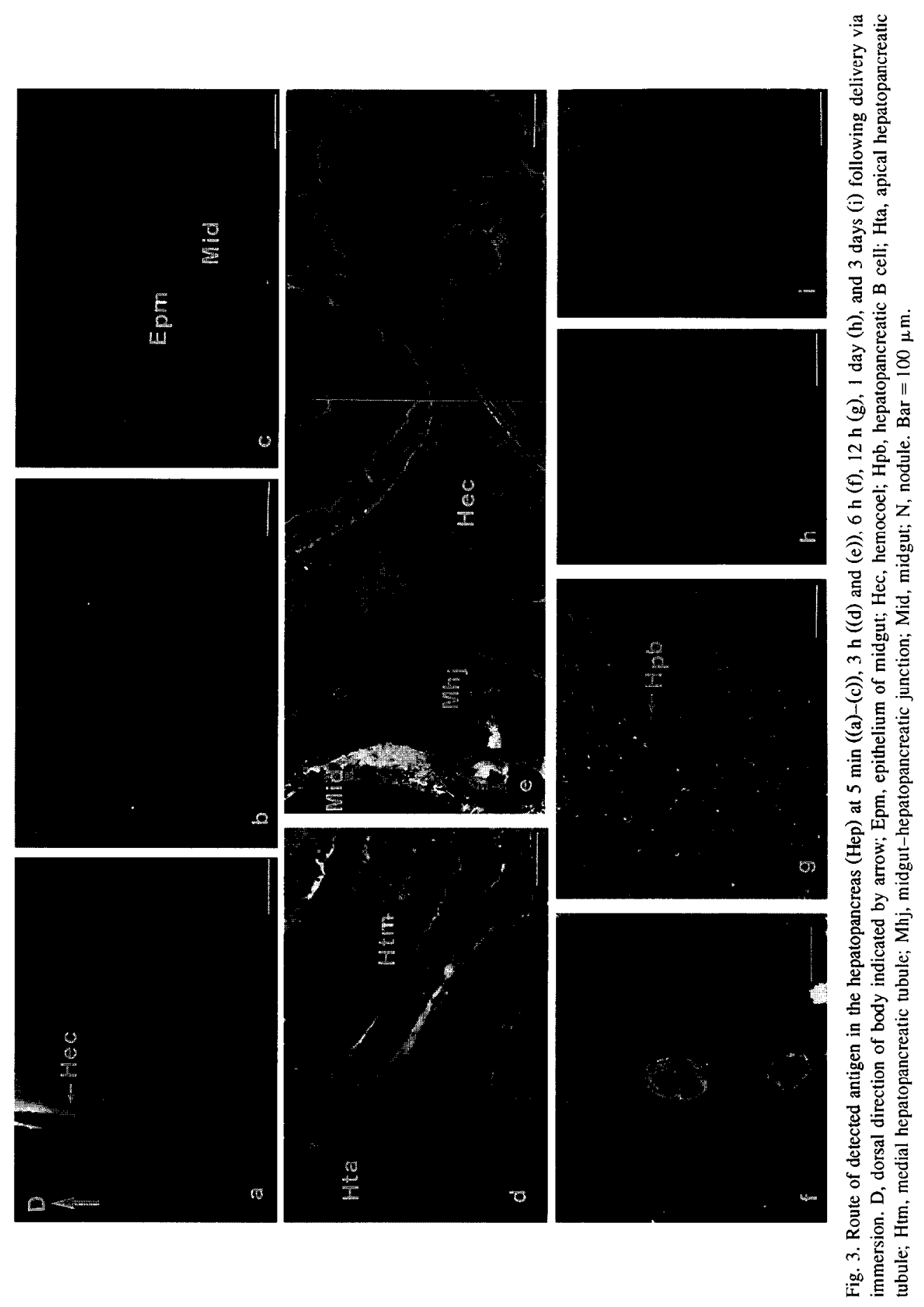




\section{Results}

\subsection{Temporal distribution of antigen}

From 5 min to $6 \mathrm{~h}$ following immersion, we detected heat-killed Vibrio antigen using an IFAT in the hemolymph, gills, stomach, hepatopancreas, midgut, hindgut, and hemopoietic tissues; however, the antigen was not detected in the lymphoid organ until 6 $\mathrm{h}$ following immersion. Fluorescence was not observed from the hindgut after $12 \mathrm{~h}$, from the hemocytes, plasma, stomach and midgut after day 3, and after day 7 it was observable only in the gill filaments and lymphoid organ-although with relatively weak fluorescence. By day 14, the antigen was not detectable in any of the tissues examined (Table 1). In addition, fluorescence was completely absent in the corresponding tissues of control shrimps and experimental shrimp stained with mAb only and secondary antibody only. The results showed that there was no autofluorescence in examined tissues of tiger shrimp.
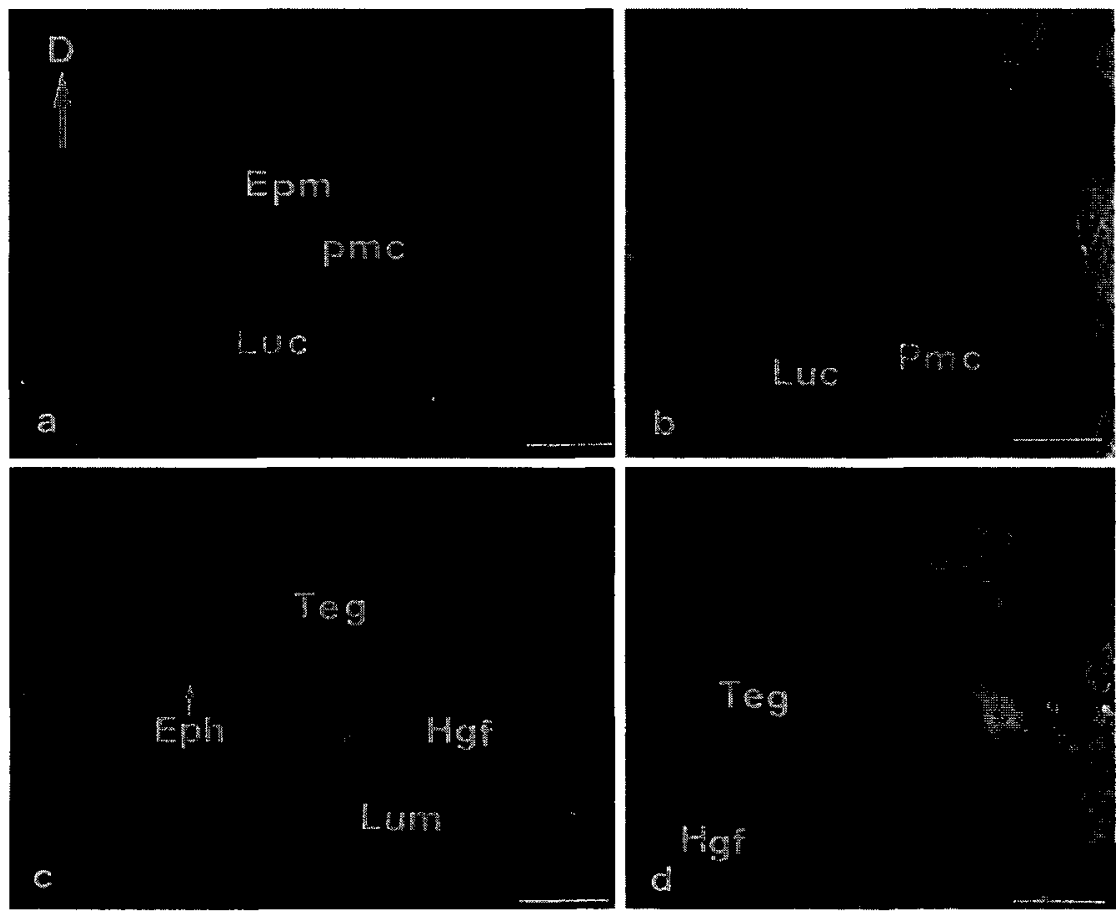

Fig. 4. Fluorescent antigen observed in the posterior midgut cecum at $5 \mathrm{~min}(\mathrm{a})$ and $3 \mathrm{~h}(\mathrm{~b})$, and the hindgut at $5 \mathrm{~min}$ (c) and $3 \mathrm{~h}$ (d). D, dorsal direction of body indicated by arrow; Epm, epithelium of midgut; Eph, epithelium of hindgut; Hgf, hindgut folds; Luc, cecal lumen; Lum, lumen; Pmc, posterior midgut cecum; Teg, tegmental gland. (a)-(c) $\mathrm{Bar}=100 \mu \mathrm{m}$; (d) bar $=25 \mu \mathrm{m}$. 


\subsection{Tissue location of antigen in digestive organs}

Immediately following immersion, the heat-killed antigen could be found in the stomach lumen (Fig. 2(a)) and setae of the gastric sieve (Gss) (Fig. 2(b)). It was then detected within the longitudinal inter-setal grooves (Lsg) (Fig. 2(c)) and at the stomach-hepatopancreatic junction (Shj) (Fig. 2(d)). However, on day 3 no antigen was detected in these tissues.
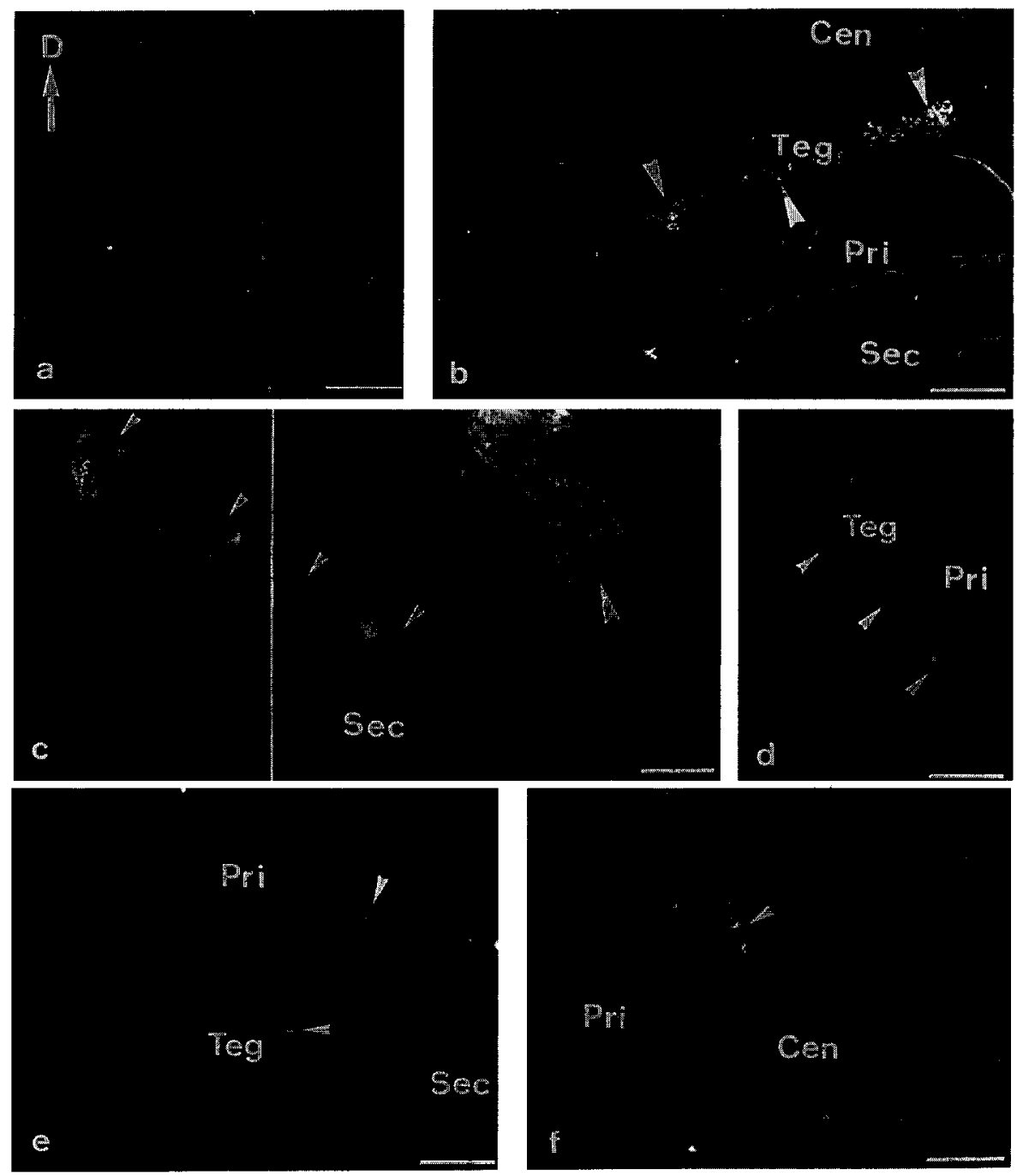

Fig. 5. Antigen detected in the gill at $5 \mathrm{~min}(\mathrm{a}), 3 \mathrm{~h}(\mathrm{~b}), 6 \mathrm{~h} \mathrm{(c),} 12 \mathrm{~h}(\mathrm{~d}), 3 \mathrm{~d}(\mathrm{e})$, and $7 \mathrm{~d}$ (f) following delivery via immersion vaccination. $\mathrm{D}$, dorsal direction of body indicated by large arrow; arrowheads, nodules; Cen, central axis; Pri, primary filaments; Sec, secondary filaments; Sin, sinus; Teg, tegmental gland. Bar $=100 \mu \mathrm{m}$. 
Also immediately following immersion, we observed the antigen in the hemocoel of the apical end (Fig. 3(a)), the lumen of the hepatopancreatic tubule in the proximal region of the hepatopancreas (Fig. 3(b)), and on the external surface of the anterior midgut epithelia located in the center of the hepatopancreas (Fig. 3(c)). The antigen then migrated to the hemocoel of the proximal region (Fig. 3(d)), and finally spread throughout the entire hepatopancreas. At $3 \mathrm{~h}$, the relative quantity of antigen increased significantly as indicated by intense fluorescence, and in addition it was observed at the midgut-hepatopancreatic junction (Mhj) (Fig. 3(e)). At 6 and $12 \mathrm{~h}$, the relative quantity of antigen decreased in the hemocoel between the tubules; however, a few nodules were formed between the tubules (Fig. 3(f)) and antigen was also observed within the B cells of the hepatopancreatic tubules (Fig. $3(\mathrm{~g})$ ). The relative quantity of antigen continued to
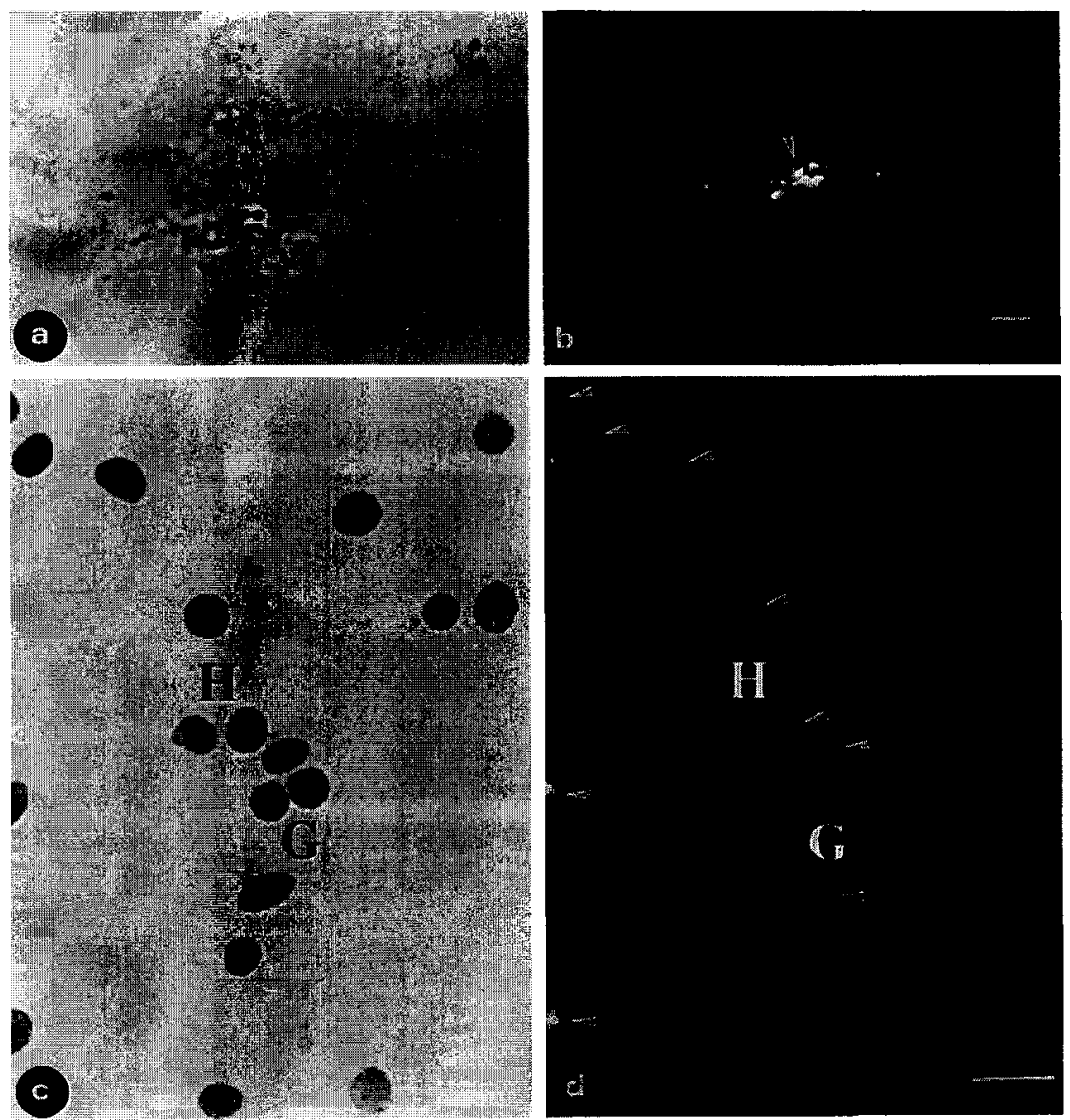

Fig. 6. Fluorescent antigen observed in the plasma at $5 \mathrm{~min}((\mathrm{a})$ and (b)) and hemocytes at $6 \mathrm{~h}((\mathrm{c})$ and (d)). Sections observed by bright field using a light microscope ((a) and (c)) and by fluorescent field ((b) and (d)). Arrow, fluorescent antigens and hemocytes; H, hyaline cells; G, granular cells. (a) and (b) Bar = $10 \mu \mathrm{m}$; (c) and (d) bar $=20 \mu \mathrm{m}$. 
progressively decrease for the rest of day 1 (Fig. 3(h)), and by day 3 the antigen concentration in the hepatopancreas was relatively low (Fig. 3(i)). By day 7, the antigen could not be detected at all in the hepatopancreas.

A mass of antigen accumulated in the anterior midgut lumen (located in the center of the hepatopancreas) immediately following immersion. This accumulation reached a maximum between 3 and $6 \mathrm{~h}$, after which it progressively declined. Also immediately following delivery, we found antigen on the external surface of both the posterior midgut cecum (Pmc) (Fig. 4(a)) and hindgut epithelia (Fig. 4(c)), as well as in the tegmental glands ( $\mathrm{Teg}$ ) in the internal region of the hindgut (Fig. 4(c)). More antigen was found in the internal region of the Pmc (Fig. 4(b)) and in the Teg of the hindgut (Fig. 4(d)) $3 \mathrm{~h}$ following treatment, but by that time the antigen had already disappeared from the outer epithelial surfaces of both these areas. By $12 \mathrm{~h}$, the antigen could not be detected in the hindgut, but could still be found in the posterior midgut up to day 3 .
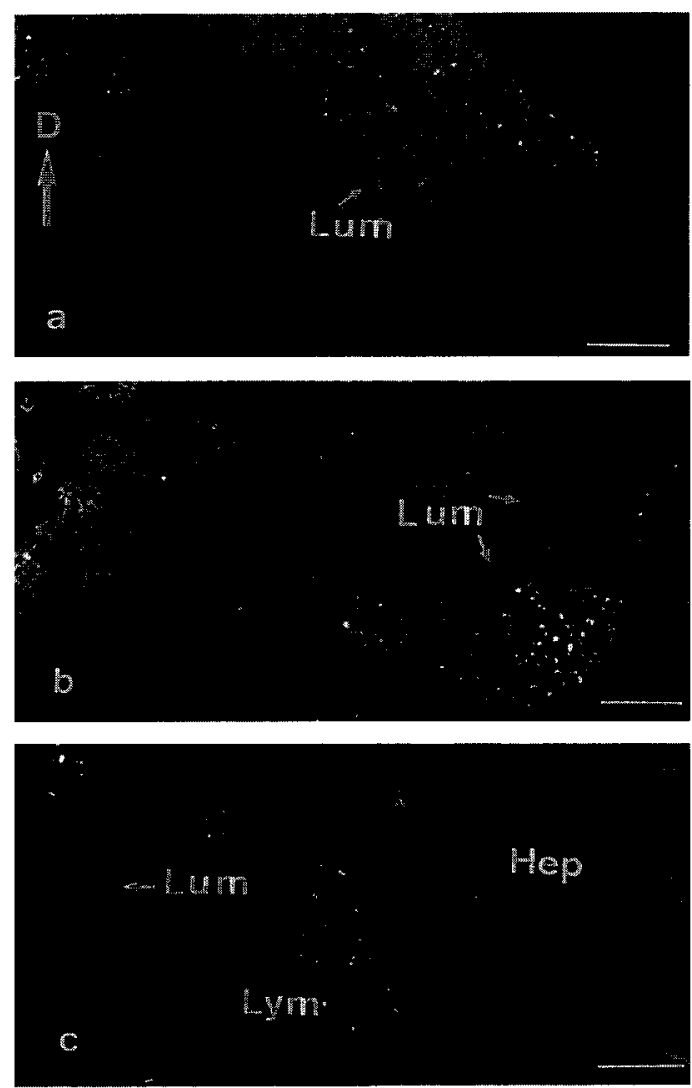

Fig. \%. Antigen in tiger shrimp lymphoid tissue at $12 \mathrm{~h}$ (a), 1 day (b), and 7 days (c) following immersion. D, dorsal direction of body indicated by arrow; Hep, hepatopancreas; Lum, lumen; Lym, lymphoid tissue. $\mathrm{Bar}=100 \mu \mathrm{m}$. 


\subsection{Distribution of antigen in gills}

We observed antigen in our experimental shrimp gills up to 7 days following delivery (Fig. 5). It accumulated on the external gill surface immediately following immersion (Fig. 5(a)), and hemocyte nodules were detectable in the Teg within the gill filaments at $3 \mathrm{~h}$ (Fig. 5(b, arrows)) and in the sinus of the central gill axis at $6 \mathrm{~h}$ (Fig. 5(c)). From 12 $\mathrm{h}$ to 7 days, we continued to observe hemocyte nodules within the gill filaments, although the number of nodules and their fluorescence decreased (Fig. 5(d)-(f)).

\subsection{Distribution of antigen in hemolymph, hematopoietic tissue and lymphoid organ}

Heat-killed Vibrio antigens were detectable in plasma from 5 min (Fig. 6(a) and (b)) to 1 day, but the relative quantity of antigen could not be determined by normal observation using an epifluorescent microscope. Concerning the amount of antigen found in hemocytes, most fluorescence adhered to the outside of the cell membrane at 5 min following immersion. We observed fluorescence within hemocytes which were almost all hyaline cells (Fig. 6(c) and (d)) from $3 \mathrm{~h}$ to 1 day, and a maximum number of fluorescent hemocytes was detected at $6 \mathrm{~h}$. Additionally, antigen was detected in the hematopoietic tissue from $5 \mathrm{~min}$ to 3 days following immersion, and we found antigen in the lymphoid organ at $6 \mathrm{~h}$ following treatment, with its fluorescence maintaining a steady level for up to 7 days before declining to zero (Fig. 7). Finally, no antigen was detected in the heart at any time during the entire observation period.

\section{Discussion}

Two phenomena were observed in this study:

1. the heat-killed Vibrio antigen was immediately detectable in the hemolymph (plasma and hemocytes) and hemocoel of the hepatopancreas following immersion;

2. the antigen appeared sequentially in the different digestive organs such as the hepatopancreas, which primarily governs digestion and absorption (Al-Mohanna and Nott, 1987).

In accordance with these two phenomena, we suggest that Vibrio antigen delivered by immersion can be absorbed by shrimp via either the circulatory or the digestive system. It appears that Vibrio antigen can also enter shrimp via the anus, since we detected Vibrio antigen in the posterior midgut and the tegmental glands of the hindgut immediately following immersion. However, by day 14 , Vibrio antigen was completely undetectable in examined tissues. This demonstrated that the persistence of Vibrio antigen in shrimp tissues was only for a short period, even though in immune response-related structures, such as lymphoid organ and hematopoietic tissue. We have found that the microbicidal reactions of both hemocytes stimulated in vitro (Song and Hsieh, 1994) and tiger shrimp stimulated in vivo via immersion (Sung et al., 1996) could be enhanced by heat-killed Vibrio antigen. Therefore, we suggest that the microbicidal reactions activated by Vibrio antigen treatment via immersion may be considered systemic in shrimp. However, this is a short-term effect. 
Vibrio antigen was detected in the digestive tissues of almost all of our experimental tiger shrimp, especially in the longitudinal inter-setal grooves, stomach-hepatopancreatic junction, midgut-hepatopancreatic junction, hepatopancreatic lumens, and the B cells of the hepatopancreatic tubules. These results show that the absorption and digestion of Vibrio antigen administered via immersion, appears to be similar to that when delivered orally. At present, it is not known whether tissues associated with disease defenses exist in the digestive system of shrimp or any other crustacean. Although we believe that antigens which can be absorbed by shrimp via the digestive system may contribute to disease resistance in shrimp, further studies are needed to elucidate whether shrimp contain disease-defense tissues and/or cells in their digestive organs, and if mechanisms are strengthened following oral antigen treatment-similar to the mucous response observed in vertebrates.

In this study, we found that the heat-killed antigen appeared almost only within hyaline cells. Previous studies on the functions of crustacean hemocytes have shown that the hyaline cells are typically phagocytic (Bauchau, 1981; Soderhall et al., 1986). Therefore, we speculate that phagocytosis can occur in hyaline cells of shrimp. However, further studies are required to determine whether other populations (semigranular and granular cells) of hemocytes can also act as phagocytes. In addition, our previous study quantified $10^{6} \mathrm{CFU} \mathrm{ml}^{-1}$ of viable bacteria in hemolymph of shrimp 5 min following water-borne infection in a concentration of $10^{7} \mathrm{CFU} \mathrm{m}^{-1}$ of bacterial suspension (Sung et al., 1996). Therefore, we estimate that the approximate amount of Vibrio antigen which was absorbed into the circulatory system should be less than one-tenth of the original concentration of immersion owing to loss of invasiveness. Further studies must be done to clarify the mechanism of entry of Vibrio antigen into the circulatory system of shrimp, and the optimum concentration of Vibrio antigen needed by shrimp to activate hemocytes and enhance disease resistance.

In addition, we believe that the nodule formation in either sinuses between the tubules of the hepatopancreas or the tegmental glands of the gills could not have resulted from infection of $V$. vulnificus or other Vibrio spp. during the experimental period, because the natural frequency of infection by $V$. vulnificus in tiger shrimp was previously found to be relatively low (Song et al., 1990), and the mAb used in this study was specific and did not cross react with other Vibrio spp. (Sung et al., 1993). Therefore, these results infer that hepatopancreas and tegumental glands of gills are somehow involved in foreign substance elimination. Fontaine and Lightner (1974) obtained the same results after observing the clearance of carmine particles in penaeid shrimp.

While the IFAT provided a specific method for detecting Vibrio antigen in shrimp tissue, it only provided a crude method for the observation of antigen locations. Moreover, this method is probably not sensitive enough to detect extremely low fluorescence levels from a single or partially disrupted bacterial cell. Therefore, the absorption of Vibrio antigen by specific tissue was observable for a 2-week time period, but not in great detail.

In conclusion, we suggest that the administration of heat-killed Vibrio antigen enhances disease resistance in tiger shrimp via systemic induction of immunity following immersion treatment. However, the short-lived nature of this phenomenon may be a 
result of the short persistence of the antigen. To prolong the duration of the enhanced resistance, we propose that shrimp are fed periodically the feedstuff containing Vibrio antigen or other immunostimulants (Sung et al., 1994), following immersion treatment.

\section{Acknowledgements}

The authors are grateful to Dr. D.V. Lightner for revising the manuscript and providing many valuable suggestions and comments. Associate Prof. Ruey-Ping Lin, Department of Zoology, National Taiwan University is also thanked for providing histological techniques. This investigation was supported by the Council of Aquaculture, the Republic of China (grant no. COA-82-BT-1.1-F-56(70-3) to Y.L. Song).

\section{References}

Al-Mohanna, S.Y. and Nott, J.A., 1987. R-cells and the digestive cycle in Penaeus semisulcatus (Crustacea: Decapoda). Mar. Biol., 95: 129-137.

Bauchau, A.G., 1981. Crustacean. In: N.A. Ratcliffe and A.F. Rowley (Editors), Invertebrate Blood Cell. Academic Press, London, pp. 387-417.

Bell, T.A. and Lightner, D.V., 1988. A Handbook of Normal Penaeid Shrimp Histology. Allen Press, Lawrence, KS, pp. 2-4.

Evensen, O., Espelid, S. and Hastein, T., 1991. Immunohistochemical identification of Vibrio salmonicida in stored tissues of Atlantic salmon Salmo salar from the first known outbreak of cold-water vibriosis (Hitra disease). Dis. Aquat. Org., 10: 185-189.

Fontaine, C.T. and Lightner, D.V., 1974. Observation on the phagocytosis and elimination of carmine particles injected into the abdominal musculature of the white shrimp, Penaeus setiferus. J. Invertebr. Pathol., 24: $141-148$.

Itami, T., Takahashi, T., Nakamura, T., Nishimura, M. and Kondo, M., 1989. Efficacy of vaccination for control of vibriosis in cultured kunuma prawn (Penaeus japonicus). J. Aquat. Anim. Health, 1: 238-242.

Itami, T., Takahashi, Y., Yoneoka, K. and Yan, Y., 1991. Survival of larval giant tiger prawns Penaeus monodon after addition of killed Vibrio cells to microencapsulated diet. J. Aquat. Anim. Health, 3: $151-152$.

Itami, T., Yan, T. and Takahashi, Y., 1992a. Studies on vaccination against vibriosis in cultured kunuma prawn Penueus japonicus-I. Effect of vaccine concentration and duration of vaccination efficacy. J. Shimonoseki Univ. Fish., 40: 83-87.

Itami, T., Yan, T. and Takahashi, Y., 1992b. Studies on vaccination against vibriosis in cultured kuruma prawn Penaeus japonicus-II. Effect of different vaccine preparations and oral vaccination efficacy. J. Shimonoseki Univ. Fish., 40: 139-144.

Lewis, D.H., 1973. Response of brown shrimp to infection with Vibrio sp. Proc. World Maricult. Soc., 4: 333.

Liao, I.C., Kou, G.H., Chen, S.N. and Lai, J.Y., 1985. Preliminary investigation on the diseases of cultured prawn in the Pingtung area. COA Fish. Ser. 4, Fish Disease Research (VII), pp. 86-94.

Lightner, D.V., 1983. Diseases of cultured penaeid shrimp. In: J.P. McVey (Editor), CRC Handbook of Mariculture, Vol. 1, Crustacean Aquaculture. CRC Press, Boca Raton, FL, pp. 289-320.

Lightner, D.V. and Lewis, D.H., 1975. A septicemic bacterial disease syndrome of penaeid shrimp. Disease of crustaceans. Mar. Fish Rev., 37: 25-28.

Liu, C.I. and Chen, M.S., 1988. Experimental infection of Vibrio sp. to induce shell disease in grass shrimp (Penaeus monodon Fabricius). Int. Fish Health Conf., Vancouver, BC, Fish Health Section, AFS, 215 pp.

Mclaughlin, P.A., 1980. Comparative morphology of recent crustacea. Freeman, San Francisco, CA.

Sindermann, C.J., 1977. Black-spot disease of fresh-water shrimp. In: C.J. Sindermann (Editor), Disease Diagnosis and Control in North American Marine Aquaculture, Vol. 6. Elsevier, New York, pp. 82-84. 
Soderhall, K., Smith, V.J. and Johansson, M.W., 1986. Excytosis and uptake of bacteria by isolated hemocyte populations of two crustacean: Evidence for cellular cooperation in the defense reactions of arthropods. Cell Tissue Res., 245: 43-49.

Song, Y.L. and Sung, H.H., 1990. Enhancement of growth in tiger shrimp (Penaeus monodon) by bacterin prepared from Vibrio vulnificus. Bull. Eur. Assoc. Fish Pathol., 10: 98-99.

Song, Y.L. and Hsich, Y.T., 1994. Immunostimulation of tiger shrimp (Penaeus monodon) hemocytes for the generation of microbicidal substances-An analysis of reactive oxygen species. Dev. Comp. Immunol., 18: 201-209.

Song, Y.I., Cheng, W., Shen, C.H., Ou, Y.C. and Sung, H.H., 1990. Occurrence of Vibrio vulnificus infections in cultured shrimp and eel in Taiwan. Proc. ROC-JAPAN Symp. Fish Disease, 1990, pp. $172-179$.

Song, Y.L., Cheng, W. and Wang, C.H., 1993. Isolation and characterization of Vibrio damsela infections for cultured shrimp in Taiwan. J. Invertebr. Pathol., 61: 24-31.

Sung, H.H., Song, Y.L. and Kou, G.H., 1991. Potential uses of bacterin to prevent shrimp vibriosis. Fish Shellfish Immunol., 1: 311-312.

Sung, H.H., Kou, G.H. and Song, Y.L., 1993. Characterization of monoclonal antibodies and corresponding epitopes of Vibrio vulnificus. Fish Pathol., 28: 181-188.

Sung, H.H., Kou, G.H. and Song, Y.L., 1994. Vibriosis resistance induced by glucan treatment in tiger shrimp (Penaeus monedon). Fish Pathol., 29: 11-17.

Sung, H.H., Yang, Y.L. and Song, Y.L., 1996. Enhancement of microbicidal activity in tiger shrimp (Penaeus monodon) via immunostimulation. J. Crustacean Biol., 16: 279-285. 